PAPER

CrossMark

\title{
The effect of $\mathrm{BaF}_{2}$ concentration and particle size distribution on the luminescence efficiency of YAG: $\mathrm{Ce}^{3+}$ phosphors
}

23 July 2018

ACCEPTED FOP PUBHCATION

26 July 2018

PUBLISHED

3 August 2018

\author{
D Valiev ${ }^{1}\left(\mathbb{1}, \mathrm{T} \mathrm{Han}^{2}\right.$, S Stepanov ${ }^{1}, \mathrm{~V}$ Vaganov $^{1}$ and V Paygin $^{1}$ \\ 1 National Research Tomsk Polytechnic University, Lenin Avenue 30, 634050 Tomsk, Russia \\ 2 Research Institute for New Materials Technology, Chongqing University of Arts and Sciences, Chongqing 402160, People’s Republic of \\ China \\ E-mail:dtdamirka@gmail.com
}

Keywords: YAG:Ce phosphors, $\mathrm{BaF}_{2}$ flux, luminescent properties, particle size distribution, luminescence decay time

\begin{abstract}
$\mathrm{Y}_{3} \mathrm{Al}_{5} \mathrm{O}_{12}$ (YAG) phosphor powders doped with $\mathrm{Ce}^{3+}$ concentration were synthesized by the solidstate reaction method with different of $\mathrm{BaF}_{2}$ flux concentration. Morphological characterization, photoluminescent properties and decay characteristics of YAG phosphor powders were studied. It was shown that $\mathrm{BaF}_{2}$ directly influenced on particle size distribution of YAG: $\mathrm{Ce}^{3+}$ phosphor. It is necessary to have both large particles agglomerates (size more than $40 \mu \mathrm{m}$ ) and small one (size less than $4 \mu \mathrm{m}$ ) to obtain high energy efficiency in polydisperse YAG: $\mathrm{Ce}^{3+}$ phosphors. It was evidenced, that the effect of both large and small agglomerates on energy efficiency is observed. The luminescence decay time for all investigated samples is significantly different in the spectral range 500 and $700 \mathrm{~nm}$ from $\tau \sim 60$ to $80 \mathrm{~ns}$, respectively.
\end{abstract}

\section{Introduction}

In past decade, light-emitting diodes (LED) are the most effective solid-state light sources [1]. Most commercially available white $\mathrm{LEDs}$ as rule consist of an InGaN blue LEDs combine with an $\mathrm{Y}_{3} \mathrm{Al}_{5} \mathrm{O}_{12}: \mathrm{Ce}^{3+}$

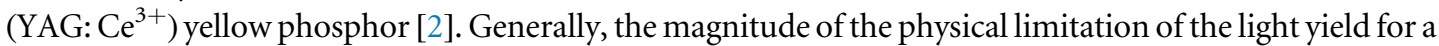
white light LED is determined by the conversion of phosphor emission into a visible light [3]. Therefore, to enhance phosphor efficiency is one of the main directions of light sources development, resource efficiency, and creating a comfortable light environment, using different physical and chemical approaches for phosphor manufacturing.

Inorganic phosphors used by most manufacturers are yttrium-aluminum garnet doped with trivalent cerium ions (YAG: $\mathrm{Ce}^{3+}$ ) synthesized with different methods. The luminescence spectrum of YAG: $\mathrm{Ce}^{3+}$ phosphors is characterized by a maximum wavelength in the spectral range of $530-560 \mathrm{~nm}$ due to emission from the $5 \mathrm{~d}$ level to the ground state $4 \mathrm{f}$ energy level of $\mathrm{Ce}^{3+}$ [4]. The most common method for the commercial manufacturing of YAG phosphors is the solid-state reaction method (SSR) [5, 6]. However, for the phosphors preparation using SSR methods is required a sufficiently long treatment at high temperatures (over $1500{ }^{\circ} \mathrm{C}$ ). The sintering process can be done in air, in an atmosphere of $\mathrm{N}_{2} / \mathrm{H}_{2}, \mathrm{~N}_{2} / \mathrm{CO}$ gas mixture [7]. This leads to partial sintering of the phosphor powder, and, consequently, it is necessary to grind the resulting mixture again. Different kinds of sintering fluxes are used to overcome the shortcomings of the SSR method [8,9]. Fluoride type flux materials such as $\mathrm{MgF}_{2}, \mathrm{CaF}_{2}, \mathrm{SrF}_{2}, \mathrm{BaF}_{2}, \mathrm{AlF}_{3}$ are efficient in the preparation of phosphor powders with garnet structures $[10,11]$. Fluxes additions have a positive influence on the ion diffusions, crystallization process as well as on the formation of YAG host with good crystallinity in the SSR method [11-15].

The introduction of $\mathrm{BaF}_{2}$ flux into the synthesis process is the most common approach in SSR route $[15,16]$. The effect of flux can be derived from YAG single crystal growth [17]. In [10] it was shown the effect of $\mathrm{BaF}_{2}$ on synthesized powder morphology of YAG: $\mathrm{Ce}^{3+}$ phosphor. The authors succeeded in achieving a high degree of particles size homogeneity when $\mathrm{BaF}_{2}$ was $5 \mathrm{wt} \%$. In addition, the grains had a spherical shape. The particle size of phosphors was 10-25 $\mu \mathrm{m}$. In [18] also was demonstrated the effect of concentrations of the $\mathrm{BaF}_{2}$ flux $(3,6,9$, 
$12,15 \mathrm{wt} \%$ ) on the morphology, crystal structure of TAG:Ce ${ }^{3+}$ phosphor with garnet structure. Particle sizes of phosphors with the addition of $\mathrm{BaF}_{2}$ had a micron size and spherical shape, regardless of the $\mathrm{BaF}_{2}$ concentration. The morphologies of the phosphor powders become spherical when the addition amount of the $\mathrm{BaF}_{2}$ flux was increased. Authors have shown that when the $\mathrm{BaF}_{2}$ concentration increase the particle size of phosphorus enhanced, without changes in the crystalline structure of TAG:Ce ${ }^{3+}$ phosphor. However, the phosphor powders prepared from the spray solution without the $\mathrm{BaF}_{2}$ flux had irregular morphologies and aggregated structure. The usage of $\mathrm{BaF}_{2}$ flux decreases of phosphor synthesis temperature, which as a result can significantly reduce power consumption and cost of phosphors production $[18,19]$. The addition of flux creates wetted microdomains, which will improve mass diffusion and accelerate solid-state reactions [20].

Another important peculiarity flux using is the effect of $\mathrm{BaF}_{2}$ on luminescent properties of YAG phosphor powders. In [10] the concentration of $\mathrm{BaF}_{2}$ changed in the wide region from 3 to $15 \mathrm{wt} \%$. The maximum photoluminescence intensity of the YAG: $\mathrm{Ce}^{3+}$ phosphor powders was observed for $9 \mathrm{wt} \%$ of $\mathrm{BaF}_{2}$ concentration. It was demonstrated that the excitation peaks position of YAG: $\mathrm{Ce}^{3+}$ phosphor does not change with increasing concentration of $\mathrm{BaF}_{2}$ [9]. This indicates that flux is chemically neutral and strong influence on optical properties of the initial powder particles of YAG: Ce phosphor. The high luminescence intensity for YAG: $\mathrm{Ce}^{3+}$ with $5 \mathrm{wt} \% \mathrm{BaF}_{2}$ phosphor was recorded.

Despite numerous studies the effect of $\mathrm{BaF}_{2}$ flux on morphology and luminescent properties of YAG:Ce phosphor, we were not able to obtain information about direct investigations devoted to the effect of flux on luminescence decay kinetics of YAG: $\mathrm{Ce}^{3+}$ phosphor. Also, the effect of low $\mathrm{BaF}_{2}$ flux concentrations with slight changes from 0.05 to $0.15 \mathrm{wt} \%$ and particle size distribution on the luminescence efficiency of YAG: $\mathrm{Ce}^{3+}$ phosphor has not been studied yet.

In this work, YAG:0.06 $\mathrm{Ce}^{3+}, x \mathrm{BaF}_{2}$ powders $(x=0 ; 0.05 ; 0.075 ; 0.1 ; 0.125 ; 0.15 \mathrm{wt} \%)$ were synthesized by the solid-state reaction in order to determine the effect of $\mathrm{BaF}_{2}$ flux doping and distribution of particle sizes on the luminescent and decay time properties. The study examined the preparation technique, the morphological characterization, luminescent properties, and decay characteristics.

\section{Materials and methods}

Phosphor powders were synthesized by high-temperature solid-state reaction method under reducing atmosphere. The preparation with this method requires repeated cycles of heating processes at high temperature up to $1600{ }^{\circ} \mathrm{C}$ to reinforce the interdiffusion and achieve a uniform single phase and homogeneity of the alloy. All reagents were a chemically pure $\mathrm{Al}_{2} \mathrm{O}_{3}(99.99 \%), \mathrm{Y}_{2} \mathrm{O}_{3}(99.99 \%), \mathrm{CeO}_{2}(99.99 \%)$, and $\mathrm{BaF}_{2}$ flux. The procedure used for the synthesis of YAG: $0.06 \mathrm{wt} \% \mathrm{Ce}^{3+}+x \mathrm{BaF}_{2}(x=0 ; 0.05 ; 0.075 ; 0.1 ; 0.125 ; 0.15 \mathrm{wt} \%)$ phosphor powders are presented in different steps. All of the initial materials were mixed in the desired ratio with the additional amount of $\mathrm{BaF}_{2}$ used as flux material with different concentration. A single phase YAG: $\mathrm{Ce}^{3+}$ phosphor was obtained at $1500{ }^{\circ} \mathrm{C}[21]$.

The obtained phosphor powders were characterized by Scanning Electron Microscopy (SEM) using a JSM7500FA microscope (JEOL, Japan). The particle size analysis was conducted using a SALD-7101 Shimadzu laser particle size analyzer (Japan). The optical reflectance spectra of the sintered phosphors were measured by a LOMO-PHOTONICS SF-256UVI spectrophotometer (Russia) in the wavelength range of 300-1100 $\mathrm{nm}$. Integrated photoluminescence (PL) spectra were acquired on an AvaSpec-3648 optical fiber spectrometer in 400-800 nm spectral range. An LED chip in pulse mode was used as excitation source for PL measurements ( $\lambda=452 \mathrm{~nm}, \mathrm{FWHM}$ is $10 \mathrm{~nm}, \mathrm{t}_{1 / 2} \sim 15 \mathrm{~ns}$ ). The photoluminescence decay kinetics was recorded with a photomultiplier tube Hamamatsu 10720-20 using a MDR-204 monochromator and a DPO3034 Tektronix (300 MHz) digital oscilloscope. The spectral power distribution of the total radiant flux of the PL spectra was measured by using an integrating sphere that was connected to a CCD detector (AvaSpec-3648) excited by an LED chip with following parameters: $\lambda=447 \mathrm{~nm}, \mathrm{FWHM} 20 \mathrm{~nm}, 16 \mathrm{~mW} \cdot \mathrm{cm}^{-2}$ irradiance.

\section{Results and discussion}

\subsection{Phosphor characterization}

SEM images analysis of all investigated phosphors shows that YAG: 0.06Ce powders with different $\mathrm{BaF}_{2}$ flux concentrations clearly consist of irregular shape and highly aggregated particles (figure 1(a)). According to the laser diffraction data, the particles have sizes from 1 to $100 \mu \mathrm{m}$ (figure 1(b)).

The results of phosphors reflection data at the excitation band $(\lambda=447 \mathrm{~nm})$ change from 4 to $8 \%$ (figure 1(c)). An estimate of the luminescence energy efficiency for all synthesized samples with a variable $\mathrm{BaF}_{2}$ flux concentration under identical conditions show in figure 1(d). It is found that the energy efficiency decreases 

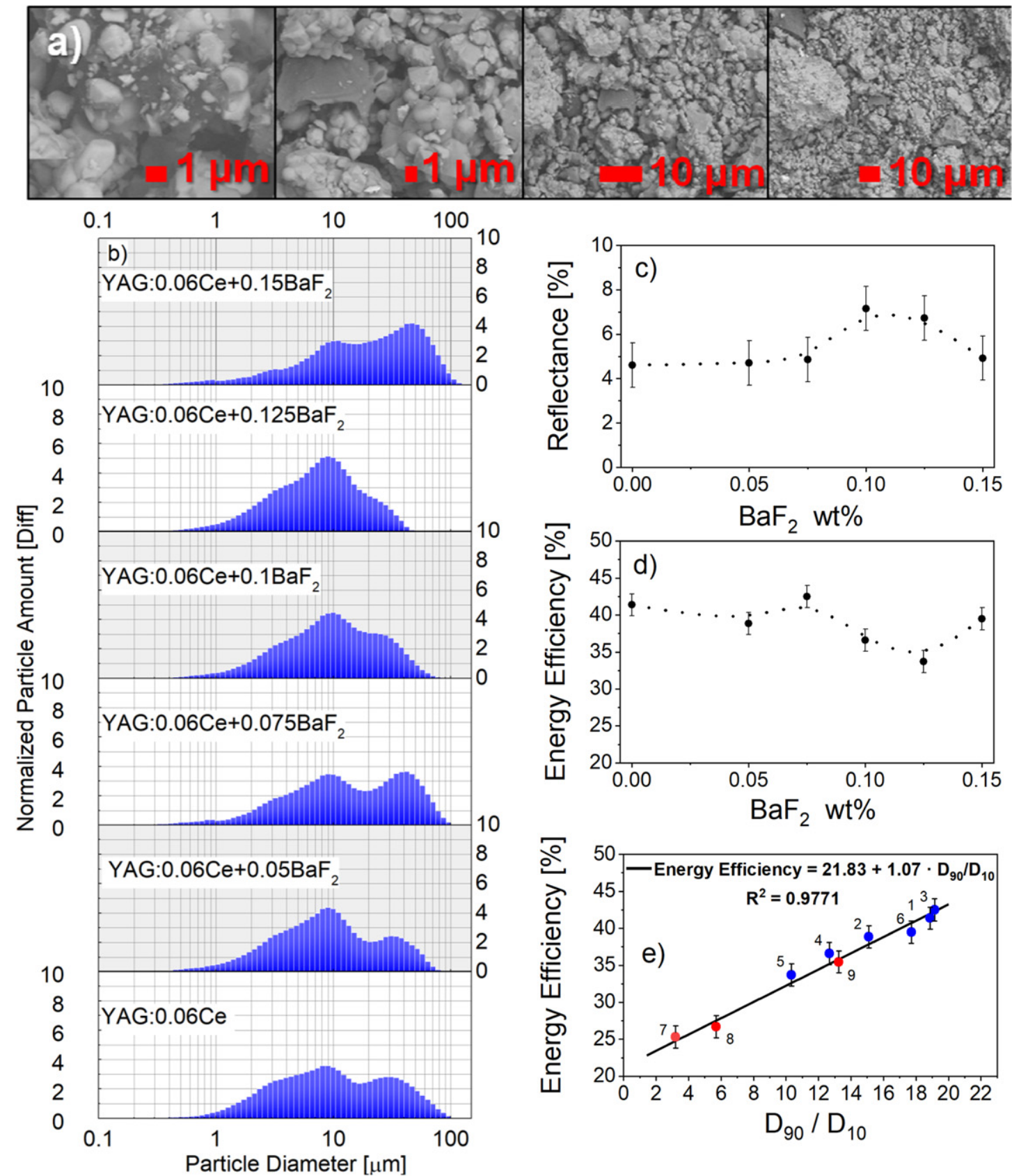

Figure 1. SEM-images (a), laser diffraction data (b), reflectance values (c), and energy efficiency (d), (e) (Points notation corresponds to table 1).

with an increase of the reflectance and varies from $33 \%$ to $42 \%$. Also reducing the sample reflection of the main absorption band at $450 \mathrm{~nm}$ is observed (figure 1(c)).

The particle size distribution for all investigated phosphors and additional data for YAG:Ce ${ }^{3+}$ phosphors with $10 \mathrm{wt} \% \mathrm{BaF}_{2}$ flux investigated earlier in [5] are presented in table 1 . We did not find a direct correlation between energy efficiency and particle agglomerate sizes of phosphor powders for $\mathrm{D}_{10}, \mathrm{D}_{50}$, and $\mathrm{D}_{90}$. However, from figures 1(a) and (d), it is evident that to obtain high energy efficiency of polydisperse phosphors it is necessary to have both large particles agglomerates (size more than $40 \mu \mathrm{m}$ ) and the small one (size less than 4 $\mu \mathrm{m})$. In order to take into account the effect of both large and small agglomerates on energy efficiency. We analyzed the dependence of energy efficiency from the $\mathrm{D}_{90} / \mathrm{D}_{10}$ ratio. The linear dependence of the energy efficiency of the YAG: $\mathrm{Ce}^{3+}$ with $\mathrm{BaF}_{2}$ phosphor on the dimensions ratio of the total size distribution of 10 and 90 mass $\%\left(D_{90} / D_{10}\right)$ powder was obtained. The data analysis is presented in figure $1(\mathrm{e})$.

It should be noted, that an increase of $\mathrm{BaF}_{2}$ concentration leads to a decrease in energy efficiency approximately on $15 \%$ of phosphor at a constant cerium concentration. Such effect was observed for YAG:Ce ${ }^{3+}$ phosphor doped with $10 \mathrm{wt} \% \mathrm{BaF}_{2}$ flux compared to YAG: 0.06Ce phosphor without flux (table 1, figure 1(e)). 
Table 1. Particle size distribution and energy efficiency of YAG:Ce ${ }^{3+}$ phosphor powders.

\begin{tabular}{|c|c|c|c|c|c|c|}
\hline & Phosphor powder & $\mathrm{D}_{10}[\mu \mathrm{m}]$ & $\mathrm{D}_{50}[\mu \mathrm{m}]$ & $\mathrm{D}_{90}[\mu \mathrm{m}]$ & Energy efficiency [\%] & $\mathrm{D}_{90} / \mathrm{D}_{10}$ \\
\hline 1 & YAG:0.06Ce & 2.15 & 8.99 & 40.63 & 41.36 & 18.88 \\
\hline 2 & YAG:0.06Ce $+0.05 \mathrm{BaF}_{2}$ & 2.21 & 8.59 & 33.39 & 38.83 & 15.10 \\
\hline 3 & YAG:0.06Ce $+0.075 \mathrm{BaF}_{2}$ & 2.56 & 12.04 & 48.95 & 42.50 & 19.15 \\
\hline 4 & YAG:0.06Ce + 0.1BaF 2 & 2.40 & 9.21 & 30.51 & 36.60 & 12.67 \\
\hline 5 & YAG:0.06Ce $+0.125 \mathrm{BaF}_{2}$ & 1.99 & 7.23 & 20.60 & 33.72 & 10.33 \\
\hline 6 & YAG:0.06Ce $+0.15 \mathrm{BaF}_{2}$ & 3.60 & 21.80 & 63.73 & 39.50 & 17.72 \\
\hline 7 & YAG:0.06Ce $+10 \mathrm{BaF}_{2}[5]$ & 3.19 & 13.10 & 10.23 & 25.30 & 3.21 \\
\hline 8 & YAG:0.04Ce $+10 \mathrm{BaF}_{2}[5]$ & 3.50 & 8.63 & 19.95 & 26.70 & 5.70 \\
\hline 9 & YAG:0.02Ce $+10 \mathrm{BaF}_{2}[5]$ & 3.17 & 12.77 & 42.04 & 35.46 & 13.25 \\
\hline
\end{tabular}

${ }^{*} \mathrm{D}_{10}, \mathrm{D}_{50}$ and $\mathrm{D}_{90}$ are the particle sizes corresponding to a cumulative distribution of 10,50 and 90 mass $\%$ of the powder, respectively. The $\mathrm{D} 50$ value corresponds to the median diameter.
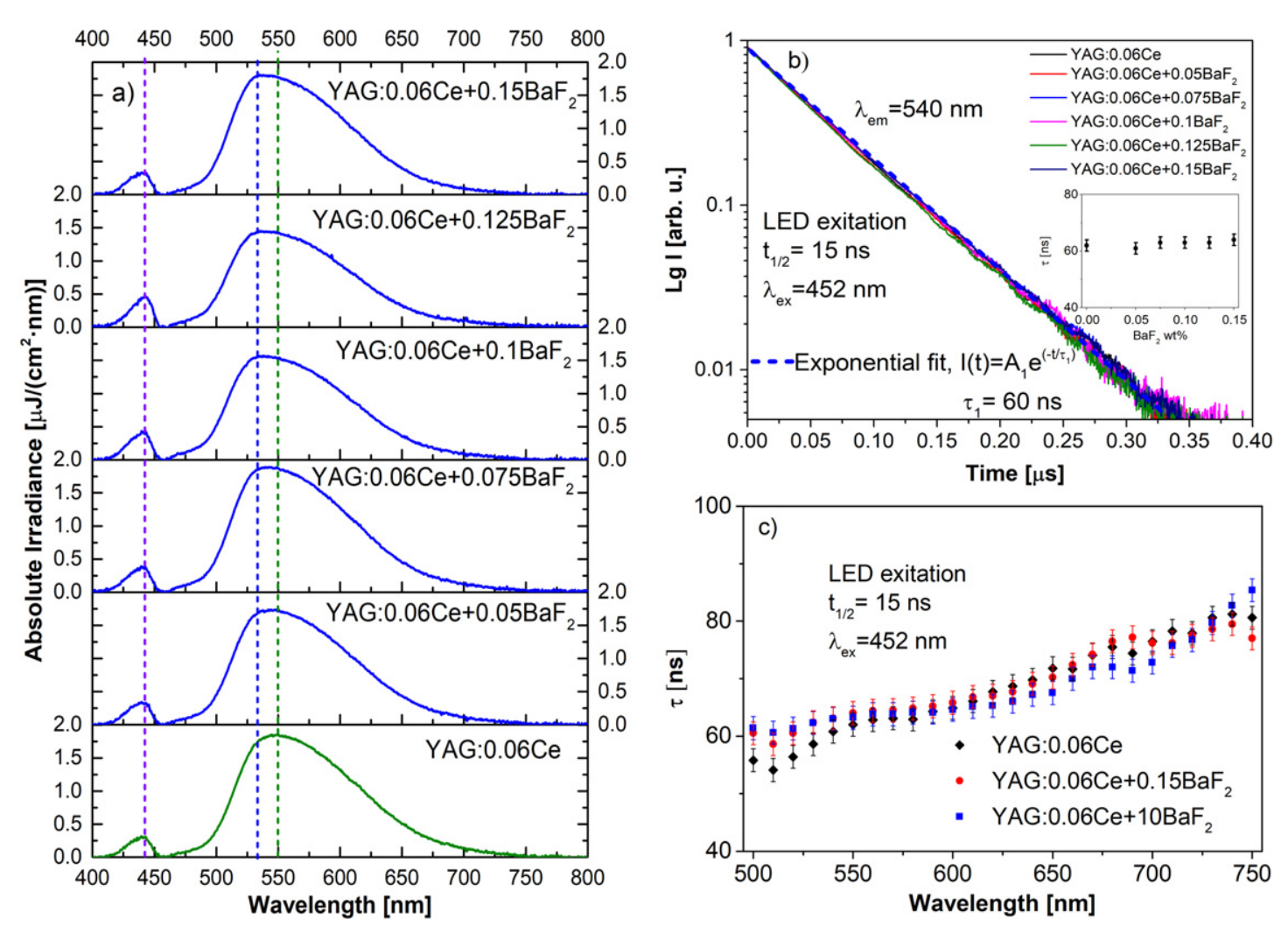

Figure 2. PL spectra $\left(\lambda_{\text {ex }}=447 \mathrm{~nm}\right)(\mathrm{a})$, luminescence decay curves (b), and dependences decay times from wavelengths (c).

In contrast, a decrease of cerium concentration at a constant barium fluorite concentration leads to an increase in the energy efficiency and agglomerates with $\mathrm{D}_{90}$ particles size (table 1). Both these processes are satisfactorily described by the obtained dependence of the energy efficiency on the $\mathrm{D}_{90} / \mathrm{D}_{10}$ ratio (figure $1(\mathrm{e})$ ).

\subsection{Photoluminescent characteristics and luminescence decay kinetics}

There are two bands in the excitation spectra monitored for the luminescence band at $\lambda_{\max }=540 \mathrm{~nm}$ with a maximum at 342 and $463 \mathrm{~nm}$. The results are similar that were obtained in our previous work [5]. These bands were recorded both for YAG:0.06Ce with and without $\mathrm{BaF}_{2}$ powders. The spectra show two excitation bands that are assigned to transitions between the 4 flowest energy level to $5 \mathrm{~d}$ splitted sublevels [22, 23].

The PL spectra of YAG: $\mathrm{Ce}^{3+}$ phosphor powders with and without $\mathrm{BaF}_{2}$ under blue LED chip excitation $\left(\lambda_{\mathrm{ex}}=447 \mathrm{~nm}\right.$ ) are not significantly different (figure 2(a)). There are two peaks at $440 \mathrm{~nm}$ and intense emission with a maximum at $550 \mathrm{~nm}$ in the luminescence spectrum of the $\mathrm{YAG}: \mathrm{Ce}^{3+}$ phosphors without $\mathrm{BaF}_{2}$ flux are recorded. However, when $\mathrm{BaF}_{2}$ flux with different concentration is introduced into YAG: $\mathrm{Ce}^{3+}$ phosphor the PL spectra of the powders are changed. The shape and the luminescence band position with a maximum at $550 \mathrm{~nm}$ possibly depend on the spin-orbit split ground state of $\mathrm{Ce}^{3+}$ ions. The crystal field surrounding $\mathrm{Ce}^{3+}$ ions splits 
the $5 \mathrm{~d}$ level into a number of sublevels. The most intense emission corresponds to the transition from the $5 \mathrm{~d}$ lowest sublevel to the two levels of the $4 \mathrm{f}$-shell. The splitting of the $4 \mathrm{flevel}$ into the ${ }^{2} \mathrm{~F}_{5 / 2}$ and ${ }^{2} \mathrm{~F}_{7 / 2}$ states leads to the doublet character of the $\mathrm{Ce}^{3+}$ emission ions [24].

The luminescence decay kinetics for all investigated powders excited by LED chip working in pulsed mode was studied. It was experimentally observed that at $540 \mathrm{~nm}$, the luminescence decay kinetics practically does not change depending on the $\mathrm{BaF}_{2}$ concentration (figure 2(b) inset). However, the luminescence decay kinetics for all investigated phosphors have is significantly different in the spectral ranges of 500-600 and 650-750 nm, respectively (figure 2(c)). In the 'green' spectral region, one component with decay time is $\tau \sim 60 \mathrm{~ns}$. The luminescence decay kinetics describes the monomolecular reaction law. The radiative transition in each center occurs independently of the state of others and determined only by their probability. Nevertheless, in the 'red' spectral range $(650-750 \mathrm{~nm})$ the decay time is $\tau \sim 80 \mathrm{~ns}$.

However, in [25] the effect of $\mathrm{BaF}_{2}$ flux on luminescence decays kinetics of $\mathrm{BaSi}_{3} \mathrm{Al}_{3} \mathrm{O}_{4} \mathrm{~N}_{5}: \mathrm{Eu}^{2+}$ phosphor prepared by the solid-state reaction was shown. Authors illustrated that for emission band at $470 \mathrm{~nm}$ of phosphors with and without flux the luminescence decay kinetics approximated by single exponential law. The decay time is slightly longer in the phosphors produced with $\mathrm{BaF}_{2}$ flux $(\tau \sim 950 \mathrm{~ns})$. This effect can be described by decreasing of defect concentration due to enhance the crystallinity. The similar effect for $\mathrm{BaMgAl}_{10} \mathrm{O}_{17}: \mathrm{Eu}^{2+}$ phosphors with LiF flux addition was observed in [26]. The authors also have been demonstrated the effect of decay time increasing for phosphor with $10 \% \mathrm{LiF}$ flux from $1.06 \mu \mathrm{s}$ to $1.17 \mu \mathrm{s}$. The process of decay time increasing connected with defect structure and enhancing of BAM:Eu ${ }^{2+}$ phosphor particles diameter.

Despite this fact, in our experimental results the effect of $\mathrm{BaF}_{2}$ flux with $0.15 \mathrm{wt} \%$ and $10 \mathrm{wt} \%$ concentration on luminescence decay kinetics of YAG:Ce phosphor does not observed. The decay time is similar for YAG:Ce ${ }^{3+}$ without $\mathrm{BaF}_{2}$ flux.

\section{Conclusion}

The structural, morphological, and optical properties of YAG:Ce phosphor powders synthesized by the solidstate reaction method with variable concentration of $\mathrm{BaF}_{2}$ flux have been studied. The influence of barium fluoride flux on the luminescent and decay characteristics was carried out.

It was shown that $\mathrm{BaF}_{2}$ directly influenced on particle size distribution of YAG:Ce phosphor. The experimental results show that it is necessary to have both large particles agglomerates (size more than $40 \mu \mathrm{m}$ ) and the small one (size less than $4 \mu \mathrm{m}$ ) to obtain high energy efficiency in polydisperse YAG:Ce phosphors. It was demonstrated that the effect of both large and small agglomerates on energy efficiency is observed. The introduction of $\mathrm{BaF}_{2}$ flux leads to an increase in luminescence intensity. The luminescence decay time for all investigated samples is significantly different in the spectral range between 500 and $700 \mathrm{~nm}$ from $\tau \sim 60$ to 80 ns, respectively.

Such effect of $\mathrm{BaF}_{2}$ flux on morphological and luminescent properties can be used for effective phosphor synthesis. This phenomenon can ultimately be substantially beneficial when used phosphors in white LEDs.

\section{Acknowledgments}

The reported research was funded by Russian Foundation for Basic Research and the government of the region of the Russian Federation, grant № 18-43-703014.

Experiments were carried out within the framework of the development program of the National Research Tomsk Polytechnic University in the project of the leading universities of the world 5-100. Project number VIUOM-205/2018.

\section{ORCID iDs}

D Valiev (iD https://orcid.org/0000-0001-6880-7642

\section{References}

[1] Yeh N, Ding T and Yeh P 2015 Light-emitting diodes light qualities and their corresponding scientific applications Renewable and Sustainable Energy Rev. 51 55-61

[2] Meyer J and Tappe F 2015 Photoluminescent materials for solid-state lighting: state of the art and future challenges Adv. Opt. Mater. 3 $424-30$

[3] Ye S, Xiao F, Pan Y X, Ma Y Y and Zhang Q Y 2010 Phosphors in phosphor-converted white light-emitting diodes: Recent advances in materials, techniques, and properties Mater. Sci. and Engin. R 71 1-34 
[4] Xia Z and Meijerink A $2017 \mathrm{Ce}^{3+}$-doped garnet phosphors: composition modification, luminescence properties, and applications Chem. Society Rev. 46 275-99

[5] Valiev D, Han T, Vaganov V and Stepanov S 2018 The effect of $\mathrm{Ce}^{3+}$ concentration and heat treatment on the luminescence efficiency of YAG phosphor J. Phys. Chem. Solid. $1161-6$

[6] Jang S, Choi Y H, Wu S, Lim T G and Yoo J S 2016 Material properties of the $\mathrm{Ce}^{3+}$-doped garnet phosphor for a white LED application J. Inf. Disp. 17 117-23

[7] Tucureanu V, Matei A and Avram A M 2015 Synthesis and characterization of YAG:Ce phosphors for white LEDs Opto-Electron. Rev. $23239-51$

[8] Ohno Kand Abe T 1994 The synthesis and particle growth mechanism of bright green phosphor YAG:Tb J. Electrochem. Soc. 141 1252

[9] Shiqing X U, Liuzheng S, Ying Z, Haidong J, Shilong Z, Degang D, Huanping W and Baoling W 2009 Effect of fluxes on structure and luminescence properties of $\mathrm{Y}_{3} \mathrm{Al}_{5} \mathrm{O}_{12}: \mathrm{Ce}^{3+}$ phosphors J. Rare Earths 27 327-32

[10] Lee S H, Jung D S, Han J M, Koo H Y and Kang Y C 2009 Fine-sized $\mathrm{Y}_{3} \mathrm{Al}_{5} \mathrm{O}_{12}$ :Ce phosphor powders prepared by spray pyrolysis from the spray solution with barium fluoride flux J. of Alloys and Compd. 477 776-9

[11] Chiang C-H, Liu T-H, Lin H-Y, Kuo H-Y and Chu S-Y 2013 Effects of flux additives on the characteristics of $\mathrm{Y}_{2.95} \mathrm{Al}_{5} \mathrm{O}_{12}: 0.05 \mathrm{Ce}{ }^{3+}$ phosphor: particle growth mechanism and luminescence J. App. Phys. 114243517

[12] Won C W et al 2011 Efficient solid-state route for the preparation of spherical YAG:Ce phosphor particles J. of Alloys and Compd. 509 2621-6

[13] Shiqing X U et al 2009 Effect of fluxes on structure and luminescence properties of $\mathrm{Y}_{3} \mathrm{Al}_{5} \mathrm{O}_{12}: \mathrm{Ce}^{3+}$ phosphors J. Rare Earths 27327

[14] Kim H, Kim J, Han J S and Park K 2016 Effect of $\mathrm{BaF}_{2}$ flux on the photoluminescence properties of $\mathrm{Y}_{2.94} \mathrm{Al}_{5} \mathrm{O}_{12}: 0.06 \mathrm{Ce}^{3+}$ phosphors for white LED applications Journal of Ceramic Processing Research 17 405-8

[15] Song Z, Liao J, Ding X, Liu X and Liu Q 2013 Synthesis of YAG phosphor particles with excellent morphology by solid state reaction J. Cryst. Growth $36524-8$

[16] Won $\mathrm{H}$ I et al 2011 Effect of metal halide fluxes on the microstructure and luminescence of $\mathrm{Y}_{3} \mathrm{Al}_{5} \mathrm{O}_{12}: \mathrm{Ce}^{3+}$ phosphors Mater. Chem Phys. 129 955-60

[17] Roberts K J and Elwell D 1981 Crystal habit and surface morphology of flux grown yttrium aluminium garnet J. Cryst. Growth 53 249-60

[18] Lee $\mathrm{S} \mathrm{H}$ et al 2009 Effects of $\mathrm{BaF}_{2}$ flux on the properties of yellow-light-emitting terbium aluminum garnet phosphor powders prepared by spray pyrolysis Opt. Mater. $31870-5$

[19] Ohno K and Abe T 1986 Effect of $\mathrm{BaF}_{2}$ on the synthesis of the single-phase cubic $\mathrm{Y}_{3} \mathrm{Al}_{5} \mathrm{O}_{12}: \mathrm{Tb}$ J. Electrochem. Soc. 133 638-43

[20] Won $\mathrm{H}$ I et al 2017 Effect of $\mathrm{BaF}_{2}$ powder addition on the synthesis of YAG phosphor by mechanical method Adv. Powder Tech. 28 50-4

[21] Wang L, Zhao F, Zhang M, Hou T, Li Z, Pan C and Huang H 2016 Preparation and photoluminescence properties of YAG:Ce ${ }^{3+}$ phosphors by a series of amines assisted co-precipitation method J. of Alloys and Compd. 661 148-54

[22] Pan Y, Wu M and Su Q 2004 Comparative investigation on synthesis and photoluminescence of YAG:Ce phosphor Mater. Sci. and Engin. B: Solid-State Mater. for Adv. Tech. 106251-6

[23] Zorenko Y, Zorenko T, Gorbenko V V, Voznyak T, Savchyn V, Bilski P and Twardak A 2012 Peculiarities of luminescent and scintillation properties of YAG:Ce phosphor prepared in different crystalline forms Opt. Mater. 34 1314-9

[24] Wiatrowska A, Keur W and Ronda C 2017 Single and multicomponent garnets nanoparticles-synthesis and luminescence J. Lumin. 1899-18

[25] Tang J et al 2013 Fine-sized $\mathrm{BaSi}_{3} \mathrm{Al}_{3} \mathrm{O}_{4} \mathrm{~N}_{5}: \mathrm{Eu}^{2+}$ phosphors prepared by solid-state reaction using $\mathrm{BaF}$ flux J. Mater. Res. 28 2598-604

[26] Wang X, Li J, Shi P, Guan W and Zhang H 2015 High dispersibility and enhanced luminescence properties of $\mathrm{BaMgAl}_{10} \mathrm{O}_{17}: \mathrm{Eu}^{2+}$ phosphors derived from molten salt synthesis Opt. Mater. $46432-7$ 